\title{
Effects of Teaching in a Summer STEM Camp on the Mathematics Teaching Self-efficacy of Highly Qualified Preservice Secondary Mathematics Teachers
}

\author{
Bridget A. Franks ${ }^{1}$, and Sheryl L. McGlamery² \\ ${ }^{1}$ Department of Teacher Education, University of Nebraska Omaha and ${ }^{2}$ Office of STEM Education, University of \\ Nebraska Omaha
}

Cite as: Franks, B.A. \& McGlamery, S.L., (2021). Effects of Teaching in a Summer STEM Camp on the Mathematics Teaching Self-efficacy of Highly Qualified Preservice Secondary Mathematics Teachers. Metropolitan Universities, 32(2), 45-67. DOI: 10.18060/25396

This is an open access article distributed under the terms of the Creative Commons Attribution License.

Editor: Valerie L. Holton, Ph.D.

\begin{abstract}
Educational opportunity gaps experienced by students of color living in poverty, with accompanying lower levels of mathematics achievement, remain a roadblock to their access to college-level training in STEM fields. To address this problem, secondary teachers must be confident in their ability to share mathematics content effectively with students from cultures different than their own. Bridging the opportunity gap is more likely with two elements in place: intellectually stimulating pre-college experiences and community partnerships that establish connections between underserved neighborhoods and resource-filled environments, such as university campuses.
\end{abstract}

This study explored the effects of teaching in a four-week STEM summer camp for ethnically diverse, high-needs middle school girls on the teaching self-efficacy of highly-qualified preservice secondary mathematics teachers, a group that has been less studied than preservice elementary teachers. Participants were students in the NebraskaMATH Omaha Noyce Partnership, a federally-funded teacher preparation scholarship program at the University of Nebraska Omaha, an urban, metropolitan university. Teaching self-efficacy was measured by the Mathematics Teaching Efficacy Belief Instrument (MTEBI) and by follow-up qualitative analysis of questionnaire responses and focus groups. Participants' gains on the MTEBI were significant for Personal Mathematics Teaching Efficacy, but not for Mathematics Teaching Outcome Expectancy. Qualitative analyses suggested that both instructional coaching and 
everyday interactions in a summer camp setting contributed strongly to the preservice teachers' increased confidence about teaching mathematics to culturally diverse, high-needs learners.

Keywords: self-efficacy, secondary mathematics teaching, opportunity gap, teacher education, STEM education

\section{Introduction}

Opportunity gaps in American schooling have emerged as important explanations for disparities in achievement, particularly in mathematics, between students in underserved schools and those who attend schools with many resources. Flores (2007) noted that Latinx, African American, and low-income students are less likely to have the same opportunities to learn in American schools as other students. Among the persistent inequities experienced by these students are less access to experienced and qualified teachers, less exposure to the high expectations of advanced classes in mathematics, and deficits in per student funding. Flores (2007) also observed that when students' ethnic or cultural background differs from that of their teachers, teachers often assume deficits in the students rather than teaching to their strengths, and these low expectations lead to fewer opportunities for learning more challenging and advanced mathematics.

The tendency among American middle and high school teachers to attribute achievement gaps to student characteristics, including motivation levels, work ethic, and family support, rather than to systemic inequities in resources and educational opportunities, has been well documented (Bol \& Berry, 2005; Locke, Tabron, \& Chambers, 2017; Tabron \& Chambers, 2019). But Kotok (2017) found that course tracking and school socioeconomic status played crucial roles in the widening achievement gap in mathematics from 9th to 11th grade between high performing African American and Latinx students and their high performing White and Asian peers. Despite similar test scores in 9th grade, high achieving Asian and White students were 25\% and 17\%, respectively, more likely than their high achieving African American and Latinx peers to be enrolled in advanced mathematics courses. Smith, Trygstad, and Banilower (2016) observed similar, tracking-related inequalities in educational opportunities for science instruction, noting that students with low prior achievement, when grouped together, have less access to wellprepared teachers, material resources, and high quality instruction. They noted further that in these classes, minority students, particularly African American and Latinx students, are significantly overrepresented.

The persistence of these opportunity gaps, and the lower levels of mathematics achievement that accompany them, reflect a common structure of unequal opportunity for students living in poverty and students of color that remains a serious concern to educators, although The National Council of Teachers of Mathematics has long asserted that: 
Much of what has been typically referred to as the "achievement gap" in mathematics is a function of differential instructional opportunities. Differential access to high-quality teachers, instructional opportunities to learn high-quality mathematics, opportunities to learn grade-level mathematics content, and high expectations for mathematics achievement are the main contributors to differential learning outcomes among individuals and groups of students." (NCTM, 2012)

Among the many suggestions made by researchers to address the opportunity gap, two elements stand out as offering significant benefits to students in underserved schools: intellectually stimulating pre-college experiences and community partnerships that bridge the gap from underserved neighborhoods to empowering, resource-filled environments (Reding et al, 2017). One such experience, the Eureka! STEM summer camp on the campus of an urban, metropolitan university, has been offered to low-income girls in Omaha, Nebraska for the past seven years. The camp includes a broad range of hands-on, experiential STEM learning activities, as well as field trips, fitness activities, and information on college and careers. It is offered by a partnership between the University of Nebraska Omaha and Girls Inc. of Omaha, a nonprofit community organization that provides many educational activities and a strong support system to girls from low-income families.

Like many summer camps, this one offers social, emotional, and physical health benefits to the students who participate. However, it can only address opportunity gaps in mathematics if the people who teach in the program can confidently and effectively offer enriched experiences, high expectations, and a growing sense of familiarity with college environments, so that students can truly envision college, and possible mathematics-related careers, in their future. Thus, the attitudes and beliefs of the people who staff the program are critical, especially those of preservice teachers who are there to gain experience working with underserved students because they intend to teach in underserved schools. College students with this goal are often not members of the same ethnic or cultural group as their future pupils; 79\% of American school teachers in 2017-2018 were White, according to the National Center for Educational Statistics. Their training should help them gain the confidence that they can communicate with students who are very different from themselves, and provide those students with high quality, challenging mathematics education.

The question explored in the present study is this: When considering their future teaching performance, are preservice secondary teachers who are highly qualified in mathematics equally confident about their ability to teach it? If not, what kinds of experiences will increase their confidence, especially when they are planning to teach high-needs students from cultural and ethnic backgrounds very different from their own? In a mixed methods study using both 
qualitative and quantitative assessments, we explored the effects of teaching in a STEM summer camp for ethnically diverse, high-needs students on the teaching self-efficacy of mathematics scholarship students in a federally-funded teacher scholarship program. Since much of the research literature on mathematics self-efficacy has focused on elementary teacher education, this study addressed the need for more study of secondary teacher preparation.

\section{Mathematics Teaching Efficacy in Preservice Teachers}

The frequent research focus on elementary education majors reflects a well-founded perception that many future elementary teachers struggle with mathematics and are lower in confidence about their ability to teach it, as well as science, than about their ability to teach other subjects (Buss, 2010). Issues explored in these studies include self-efficacy regarding actual performance on mathematics problems, mathematics anxiety, mathematical beliefs, and self-efficacy about teaching mathematics.

Much of this research draws on Bandura's (1986) social cognitive theory, wherein self-efficacy is defined as people's judgments about their capacity to organize and execute a course of action needed to produce a specific performance attainment. It is concerned "not with the skills one has but with the judgments of what one can do with whatever skills one possesses" (Bandura, 1986, p. 391). As noted by Bates, Latham, \& Kim (2011), self-efficacy mediates between beliefs and behaviors, so regardless of their actual mathematical ability, students' efforts may be affected by their own judgment of their ability to solve mathematics problems or perform other mathematics tasks.

Assessment of self-efficacy for mathematics teaching is thus a critical aspect of teacher training, since preservice teachers who do not believe they can teach a subject effectively are less likely to persevere in learning to do so. Such assessment forms the basis for many research studies of teachers' beliefs about their ability to teach mathematics. The Mathematics Teaching Efficacy Belief Instrument, or MTEBI (Enochs, Smith, \& Huinker, 2000) is often used for this assessment. The instrument is useful because it measures two dimensions of self-efficacy: belief in one's own ability to teach effectively, and belief that effective teaching in general will have a positive effect on student learning. The subscale that measures the first dimension is called Personal Mathematics Teaching Efficacy (PMTE); the subscale for the second dimension is called Mathematics Teaching Outcome Expectancy (MTOE).

Two types of studies have made use of the MTEBI: those that explore relationships among mathematics teaching self-efficacy and other beliefs or attitudes, and those that explore pre- and post- effects of interventions, such as methods courses or field experiences. In the former type of study, a number of interesting relationships have been observed. Bates, Latham, and Kim (2011) found that performance on a mathematics basic skills test was strongly correlated to both 
mathematics self-efficacy, as measured by the Mathematics Self-Efficacy Scale, and mathematics teaching efficacy, as measured by the PMTE subscale of the MTEBI. Preservice elementary teachers who felt confident about their ability to solve mathematics tasks were more likely to feel confident about their ability to teach mathematics to children.

Briley (2012) explored the relations among mathematics self-efficacy, mathematics teaching self-efficacy based on the MTEBI, and the level of sophistication of preservice elementary teachers' beliefs about mathematics (e.g., whether it is viewed as a set of isolated facts and procedures or as coherent concepts; whether it is to be memorized or to be understood). Preservice teachers who reported stronger beliefs in their ability to teach mathematics effectively were more likely to hold sophisticated mathematical beliefs. Both mathematical beliefs and mathematics self-efficacy were positive predictors of mathematics teaching self-efficacy, particularly on the PMTE subscale.

With regard to the effects of interventions, Swars, Daane, and Giesen (2006) used the MTEBI to explore the relationship between mathematics anxiety and mathematics teaching self-efficacy among elementary preservice teachers taking a mathematics methods course that included 24 days of clinical experience in elementary schools. Even after the course, where no pretesting was done, they found a significant, moderate negative relationship, such that preservice teachers with the lowest levels of mathematics anxiety had the highest scores on the PMTE subscale.

Other studies, however, have found that supportive experiences in mathematics content courses, methods courses, and field experiences can have positive effects on teaching self-efficacy. Newton, Leonard, Evans and Eastburn (2012) used the MTEBI to explore the relationship between content knowledge and teaching self-efficacy during an elementary mathematics methods course that included field experiences in urban public schools. Throughout the course, they observed a moderate positive relationship between mathematics content knowledge and the PMTE subscale of the MTEBI, as well as increases in both mathematics content knowledge and scores on the PMTE subscale.

In a two-course sequence of elementary mathematics methods and student teaching, Swars, Hart, Smith, Smith, and Tolar (2007) used the MTEBI to explore the relationships among mathematics content knowledge, pedagogical beliefs, and teaching efficacy. Self-efficacy beliefs on the PMTE subscale increased over time in both methods courses and student teaching. Utley, Mosely, and Bryant (2005) also found that preservice elementary teachers' personal self-efficacy for teaching mathematics had increased by the end of their methods courses. 


\section{Mathematics Teaching Efficacy in Preservice Secondary Mathematics Teachers}

Concern about elementary teachers' self-efficacy for teaching mathematics is understandable, since elementary teachers with high mathematics anxiety may avoid teaching mathematics in their classrooms or use less sophisticated teaching methods (Karp, 1991; Swars, Daane, \& Giesen (2006). Teachers who have high efficacy about teaching mathematics are more likely to use inquiry-based and student-centered teaching methods, thus increasing both student interest and achievement (Swars, Hart, Smith, Smith, \& Tolar, 2007).

Fewer studies have explored secondary teachers' self-efficacy for teaching mathematics. One reason for this is that secondary mathematics teachers have chosen the field, whereas elementary teachers, whether they enjoy mathematics or not, are still required to teach it in most elementary schools. If secondary-education students feel uninterested or less than confident about their mathematics knowledge, they can choose another academic discipline and select out of any expectation that they teach mathematics. This being the case, we might assume that those who choose to teach mathematics at the secondary level are reasonably confident in their mathematics skills and content knowledge. In general this appears to be true, and such confidence can affect career choices, as noted by Hackett and Betz (1989), who found correlations between mathematical performance, mathematics self-efficacy, and choosing a mathematics-related major in college.

But performing mathematics tasks skillfully is not the same as teaching mathematics. Secondary mathematics teachers, in addition to teaching students who share their enjoyment of the subject, must teach students who are not like themselves, that is, students who do not enjoy it and may have high levels of mathematics anxiety and low levels of background knowledge and achievement. If the teachers are White and middle-class, as many American teachers are, they must also learn how to connect with students whose race, culture, and socioeconomic context differs from their own. Secondary students who have experienced opportunity gaps, including many years of less-than-optimal education in high-poverty environments, may not have received the encouragement to pursue mathematics that their teachers did, and may be unmotivated. Despite these challenges faced by preservice secondary mathematics educators, few studies have explored their self-efficacy for teaching mathematics.

Two explorations with a small sample of new inservice secondary teachers taking a mathematics methods course while teaching for the first time (Evans, 2011a; 2011b) illustrated some interesting relationships. Evans' (2011a) study of 42 Teaching Fellows in a New York City alternative certification program found a positive correlation between attitudes toward mathematics, including confidence, value, enjoyment, and motivation, and the Personal Mathematics Teaching Efficacy subscale of the MTEBI, but not between such attitudes and the Mathematics Teaching Outcome Expectancy subscale. Both content knowledge in mathematics 
and attitudes about mathematics improved significantly by the end of the semester, but there was no significant change between pretest and posttest scores on either of the MTEBI scales. Taking a methods class while gaining teaching experience was clearly helpful in some ways, but it did not result in increased self-efficacy for teaching mathematics.

In another analysis of the same sample, Evans (2011b) found that the mathematics and science majors among the teachers had higher mathematics content knowledge than other majors, but content knowledge was not related to either attitudes toward mathematics or teaching selfefficacy, as measured by the MTEBI. Teachers reported high positive attitudes toward mathematics and high teacher self-efficacy, regardless of their content ability. This study used a small convenience sample of teachers in a unique educational environment; they were careerchangers recruited to an alternative certification program and had provisional teaching certification while taking graduate courses in education and teaching in their own classrooms (Evans, 2011b). It is interesting that their self-efficacy beliefs on the MTEBI subscales did not change significantly over the course of their first semester teaching, but the uniqueness of their situation makes these findings difficult to generalize.

Teaching self-efficacy was explored in another unique context by Haynes and Stripling (2014), who used the MTEBI to examine the mathematics teaching self-efficacy of agriculture education teachers in Wyoming. Their participants were moderately self-efficacious in both Personal Mathematics Teaching Efficacy (PMTE) and Mathematics Teaching Outcome Expectancies (MTOE). Professional development needs reported by teachers varied based on their selfefficacy, with teachers lower in self-efficacy desiring help with procedural elements such as concepts in common core mathematics and designing lesson plans that utilize agriculture. Teachers higher in self-efficacy wanted professional development in teaching mathematics concepts found in natural resource management and plant science, collaborating with mathematics teachers, and motivating students to learn the mathematics found in the agricultural and natural resources curricula. Higher self-efficacy in these teachers appeared to be associated with teaching at a more advanced level, thus providing students with more challenging experiences.

\section{Rationale for the Current Study}

The studies above (Evans, 2011a; 2011b; Haynes \& Stripling, 2014) were completed with inservice teachers; there is a need for more work with preservice secondary teachers, particularly those who are near the beginning of their training. Because of a partnership between the University of Nebraska Omaha and Girls Inc. of Omaha, the teacher education program at this university has been able to provide field experiences for students (both elementary and secondary majors) in (Eureka! STEM, a summer camp for educationally at-risk middle school girls. One group of such students is comprised of Noyce Scholarship recipients. These undergraduate students have been selected for the NebraskaMATH Omaha Noyce Partnership,

(C) The Author 2021. Published by the Coalition of Urban and Metropolitan Universities. www.cumuonline.org Metropolitan Universities | DOI 10.18060/25396 | August 16, 2021 
an effort funded by the National Science Foundation Robert Noyce Teacher Scholarship Program. They are highly-qualified students in mathematics, are majoring in mathematics and secondary education, and participate in the camp at an early stage in their program. Their mathematics competency has already been demonstrated, but how confident are they about the realities of teaching mathematics to ethnically diverse students who need substantial academic support?

This study explored the effects of teaching in a STEM summer camp with ethnically diverse, high-needs students on preservice secondary mathematics teachers' teaching self-efficacy, as measured by the MTEBI, and also by follow-up qualitative analysis of questionnaire responses and focus groups. The qualitative analysis was designed to expand understanding of the quantitative results, and of the experience as a whole. If the STEM summer camp experience affected teaching self-efficacy, whether positively or negatively, what were the reasons? Which aspects of the program made the greatest difference to the students? The authors were particularly interested in students' reactions to the instructional coaching provided to them throughout the summer camp session.

A number of research studies have been produced in the seven years of the summer STEM camp's operation. In the authors' previous work (Franks, McGlamery, \& Van Wyngaarden, 2016; McGlamery, Franks, \& Shillingstad, 2016; McGlamery \& Franks, 2019), they have observed significant improvements in the science teaching self-efficacy of preservice elementary teachers who completed an intermediate field experience during the summer camp, and have also compared the summer camp experience with regular, classroom-based field experience in terms of science teaching self-efficacy. An earlier study by other researchers (Reding et al., 2017), examined the quantity and strength of relationships between the Eureka! STEM camp participants and student camp leaders who were scholarship recipients and future mathematics teachers. The present study focused on a different sample of these scholarship participants, exploring the effects of the experience on their self-efficacy for teaching mathematics.

\section{The Summer Camp Field Experience}

The summer STEM camp is offered in a city school district in which about $72 \%$ of students identify as a racial or ethnic minority. Of these students, 34.9\% identify as Hispanic/Latinx, 28\% as White, $25.2 \%$ as African American, and 5.6\% as Asian. The remainder include biracial students and students identifying as Native American and Pacific Islander. In the district, 19\% of students are English Language learners and 74\% receive free or reduced lunch (Omaha Public Schools).

The four-week summer camp experience introduces at-risk female students, who are rising 7th and 8th graders from low-income families, to STEM education in a positive college setting, with the goal of stimulating their interest in both academic success and possible future careers in 
STEM fields. Topics in the camp included robotics, high-altitude ballooning, rocketry, programming and coding, financial literacy, physics, biology, biomechanics, chemistry, engineering and mathematics. The mathematics sessions in the Eureka! STEM camp addressed middle level, 5th through 8th grade, mathematics concepts. Some pre-algebra and algebra concepts were introduced.

In the city school district, students are tested using the Nebraska Student-Centered Assessment System in Mathematics. Three levels of proficiency are determined based on test performance: Developing, On Track, and College and Career Ready (CCR). Proficiency in meeting state standards is calculated based on the scores of students achieving at the On Track and CCR levels. In the 2018-2019 school year, the percentages of students reaching proficiency in mathematics were $48 \%$ for White students, $25 \%$ for Hispanic/Latinx students, and $17 \%$ for African American students (Nebraska Department of Education).

Most camp participants needed additional support in mathematics; on average they demonstrated a one- to two-year achievement gap in comparison with their middle-class peers in the city, a trend that has been observed every year of the seven years the camp has operated. Camp staff introduced more mathematics-based sessions to target important mathematics standards, and reviewed concepts the girls should have learned in upper elementary and middle level mathematics classes.

All of the girls were recruited for the summer camp via a community partner of the teacher education program, Girls Inc. of Omaha, a community support program for girls. Most of the participants were from single parent families with annual incomes below $\$ 30,000$. The majority were African American, but African (Somali), Latina, and White girls also participated. Girls Inc. of Omaha serves girls ages 5 through 18 years of age. Founded in 1975, it now has two centers in the city, with art rooms, computer labs, and a library, woodshop, sports field, and playground. It serves approximately 1,000 girls each year, providing after-school programming, mentoring, college application assistance, transportation, counseling services, medical services, healthy meals, and computer access. The summer STEM camp is part of a five-year program collaborative offered by Girls Inc. of Omaha and the University of Nebraska Omaha. The first two years focus on the summer camp, and the following years include mentorship and externship experiences with STEM-related organizations and businesses.

\section{Research Questions}

In this study the authors used a mixed methods approach known as the explanatory sequential design, so called because researchers first collect quantitative data and then gather qualitative data to help explain or elaborate on the quantitative results (Creswell \& Guetterman, 2019). The quantitative analysis explored this question: how does teaching in a STEM summer camp affect preservice secondary teachers' personal mathematics teaching efficacy beliefs and/or 
mathematics teaching outcome expectancy, as measured by the MTEBI? The qualitative inquiry expanded on this question to explore more deeply, via an open-ended questionnaire and a focus group, the aspects of the Eureka! STEM program that were most likely to impact participants' teaching self-efficacy. These aspects included their experiences as instructors in the summer camp, the effects of the instructional coaching they received as they prepared and carried out lessons, and their interactions with students from diverse cultural backgrounds.

\section{Method}

\section{Participants}

Participants in the study were undergraduate students at a medium-sized metropolitan university who had been selected for mathematics scholarships in a federally-funded Teacher Scholarship Program. The program is open to students enrolled in the university's Bachelor of Science in Mathematics/Teacher Preparation program. The grant provides scholarships, research opportunities, internships and mentorship to students pursuing careers as high school mathematics teachers in high-needs schools. Scholarship participants earn both a mathematics degree and secondary teacher certification while developing valuable skills, such as culturally responsive teaching techniques, that will enable them to teach effectively in high-needs schools.

The study participants, known as interns, were all preservice secondary mathematics teachers, enrolled in a summer teaching course for which the Eureka! STEM camp experience served as a field component. The goal in incorporating the interns was to give them teaching experience with diverse populations of youth, and also for them to provide needed support to the instructors who were leading the STEM sessions of the camp. There were 10 interns, including four White males and six females, five of whom were White and one African-American.

\section{Intern Activities}

The interns were assigned to work with an instructor during each STEM session. Since the session contents were all different, efforts were made to pair interns with areas in which they had expressed an interest. Each intern worked in an instructional capacity for five hours per day, four days per week. Friday sessions were field trips to various STEM-focused sites that provided the girls with new and interesting experiences; the interns accompanied the girls on all of their field trips.

Each STEM session was 90 minutes in length. Each intern designed, planned, and taught two 90minute, all-mathematics sessions, with the assistance of the instructional coach. In addition, the interns worked with presenters in other STEM areas to assist as instructional facilitators and group managers. 


\section{Instructional Coaching and the Intern Experience}

During the four-week camp session, the interns were given instructional coaching before they taught, during the teaching process, and after the teaching sessions. The instructional coaching was designed to better assist these novice teachers as they planned and implemented lessons. Because the interns were novice teachers, they needed assistance with planning lessons that were inquiry based and engaging to the girls. The instructional coach met with the interns weekly, and also attended their teaching sessions to observe them and give feedback on their teaching. The meetings were opportunities for discussions about best teaching practices and a chance to plan together the lessons the interns would be teaching. The mathematics instructional coach was a former teacher of mathematics with a $\mathrm{PhD}$ in mathematics education, who also worked as an instructional coach of mathematics for a local school district before joining the faculty at the university.

\section{Quantitative Data Analysis}

\section{Instrument}

The Mathematics Teaching Efficacy Belief Instrument (MTEBI) (Enochs, Smith, \& Huinker, 2000) was used to assess the interns' self-efficacy regarding mathematics teaching. This instrument measures two subscales, Personal Mathematics Teaching Efficacy Belief (PMTE) (13 items), and Mathematics Teaching Outcome Expectancy (MTOE) (8 items). Participants' beliefs are rated on a 5-point Likert scale ranging from 1 (strongly disagree) to 5 (strongly agree). Each subscale contains both forward-phrased ("I will continually find better ways to teach mathematics") and reverse-phrased ("I will not be very effective in monitoring mathematics activities") items.

\section{Procedure}

The MTEBI was administered to the interns at the first organizational meeting, one week before the camp was to begin. The posttest administration of the MTEBI occurred at the last meeting of the interns, during the last week of the summer camp.

\section{Results for Quantitative Analysis}

Paired samples $t$ tests were used to evaluate differences between pretest and posttest scores for the two subscales of the MTEBI, Mathematics Teaching Outcome Expectancy (MTOE) and Personal Mathematics Teaching Efficacy (PMTE). Table 1 illustrates the results observed for the two subscales. 
On the MTOE subscale, the difference between pretest and posttest scores was not significant, $t$ $(9)=1.64, p=.14$. An average difference of 1.9 points between pretest and posttest scores was observed. On the PMTE subscale, the difference between pretest and posttest scores was significant, $t(9)=3.99, \mathrm{p}=.003$. An average difference of 5.1 points between pretest and posttest scores was observed (Table 1). Using an Eta ${ }^{2}$ formula for a paired samples $t$ test, a large effect size of .23 was obtained for the MTOE subscale and an even larger effect size of .63 was obtained for the PMTE subscale (Cohen, 1988).

Table 1. Paired samples t-tests with pretest and posttest scores on Mathematics Teaching Outcome Expectancy and Personal Mathematics Teaching Efficacy subscales of the MTEBI, Interns Summer Camp Sample

Interns, Summer Program

\begin{tabular}{|lllllll|}
\hline Subscale & $\mathrm{N}$ & Mean, SD Pre & Mean, SD Post & $t(9)$ & $p$ & Effect size* \\
\hline MTOE & 10 & $30.8(2.44)$ & $32.7(3.16)$ & 1.64 & .14 & .23 \\
\hline PMTE & 10 & $53.4(4.25)$ & $58.5(4.71)$ & 3.99 & .003 & .63 \\
\hline
\end{tabular}

MTOE scores out of 40 possible; PMTE scores out of 65 possible. *Eta ${ }^{2}$ values: .01 = small effect, $.06=$ moderate effect, $.14=$ large effect (Cohen, 1988)

\section{Qualitative Data Analysis}

Procedure

The qualitative data was collected via a written survey with open-ended questions, as well as oral responses in the context of focus group interactions. The written responses collected on the questionnaire were used as a beginning point for further conversation with the interns. The questionnaire was given to the interns during their second to last meeting with their instructional coach. The focus group occurred at the final meeting with the instructional coach. All 10 interns responded to the questionnaire and participated in the focus group discussions. The written questionnaire included the following questions:

\section{Questions about the Eureka! STEM Camp Experience:}

1. What about the Camp did you like best?

2. What aspects of the Camp most interested you?

3. Were there aspects of the Camp that you did not expect? 


\section{Questions about the Coaching Experience:}

1. What about the instructional coaching did you find useful?

2. What aspects of the instructional coaching did you find least useful?

\section{Questions about Teaching Students:}

1. What challenges did you have working with the girls?

2. What successes did you have working with the girls?

\section{Qualitative Analysis}

The qualitative data was collected in two ways. First, the written questionnaire was administered, and based on the responses to the questionnaire, possible follow-up questions were planned to be asked during the face-to-face focus group session.

The questionnaire responses were sorted and coded for common themes, using the constantcomparative method described by Bogdan \& Biklen (2007). In this method, researchers look for key issues, words, or phrases in data that become coding categories. They compare incidents in the data to other incidents, incidents to categories, and categories to other categories (Creswell \& Guetterman, 2019). They examine the coding categories for overlap or redundancy, then collapse them into broad themes.

The focus group setting allowed the interns to clarify and provide more detail about their written responses. The focus group data was recorded as field notes and meeting minutes by the author and the instructional coach. These notes were also coded, with the goal of identifying additional themes and confirming themes identified from the written responses. The coding process, including both the written surveys and the focus group, identified the following themes:

- Lack of experience with a diverse population of students

- Class differences (interns mostly came from middle-class families; students were from families living in poverty).

- Challenges related to the age of the students, such as selecting developmentally appropriate mathematics lessons.

- Emotions surrounding the experience, such as anxiety, feeling overwhelmed

- Developing a relationship with the students in the camp

- Learning to gain the students' trust

- Helping the students take risks to try new mathematics activities, particularly those that were challenging

- Challenges related to interns' newness to teacher preparation

- Benefits of coaching

- Feelings of anxiety relieved by support from the instructional coach

- Sense of improvement in their own teaching skills

- Usefulness of the camp experience as part of their preparation to teach mathematics 


\section{Results}

The themes identified and confirmed by the questionnaire and the focus group session formed the basis for the assertions below. Quotations from the participants are used to support the assertions and provide the reader with the perspective of the study participants.

\section{Assertion One}

The biggest challenge to the efficacy of the interns was working with such a diverse population of students. Because the interns were in the beginning of their teacher preparation, they lacked experience and confidence to tackle the teaching challenges they faced during the summer camp. They struggled initially with gaining the students' trust and developing relationships with girls whose family situations were mostly very different from their own.

Intern \#4: "Learning to relate to the girls and establish a working relationship was the challenge for me. The question up front was, how do I gain the girls' trust? How do I get the girls to follow my instructional lead? Many of the girls struggled with math and needed to feel comfortable with the instructor in order to try. Being able to establish trust and lead the girls to take risks and try really was exciting to experience."

Intern \#9: "I was surprised to see how different the girls were at first. I don't know what I expected. They seemed so young and I had no idea how to start to get to know them."

Intern \#10: "The diversity was hard to deal with, where do I begin? What type of teaching will we be doing? Do I even know what level of math to consider teaching? Do the girls even like math? All these questions, it was hard not to panic."

\section{Assertion Two}

Interns reported that the opportunity to work with diverse learners was helpful in developing efficacy in teaching mathematics. However, the initial orientation to the setting was anxiety producing. All but two of the interns had not worked with such diverse learners. The girls participating in the camp were from diverse backgrounds, and the interns reported that middle level students were a new experience for all but two of them. Additional issues centered on concerns about classroom management and how to best engage the girls in learning. Learning levels and how to select developmentally appropriate math lessons were foremost in the minds of the interns. 
Intern \#2: "Middle level students were new to me. I have only worked with college students. The behaviors and the needs of middle level girls seemed to offer some challenges I didn't know how to address. The overall experience with the diversity was good, just overwhelming at first."

Intern \#4: "Wow, the girls were great, once I got into the sessions and had a chance to work one on one with them. It certainly was a matter of getting to know the students and establishing trust with the students. The math sessions helped me see the need for experience with diverse learners. Coach J was right about being prepared to meet the learners where they are. Yes, it helped me feel confident in my ability to teach math."

Intern \#5: "The big question for me was where do we begin to teach math to such a varied group of students? It was so cool to have the opportunity to go from not knowing how to grab onto this, to being able to do two major teaching sessions and have it all come together. Working as a team with other interns and the instructional coach was really good. It gave me more confidence to try things and explore new ways of teaching."

\section{Assertion Three}

Interns reported that the coaching experience was very useful in helping them achieve greater efficacy in teaching mathematics. The coach assisted with the planning of the mathematics lessons taught by the interns and helped the teacher candidates to reflect on the teaching experiences after the lessons concluded. A particular challenge was helping the girls, who did not have strong mathematics skills, learn to take risks and try new mathematics activities. In this, the coach modeled assessing what the girls did know and adapting activities to be more user friendly for them. All the interns found the coaching experience to be the most useful aspect of working in the camp.

Intern \#1: "Many of the girls we worked with were behind in their math skills. It was very important to have math lessons that fit the level of the student. If the lesson is too hard the girls tend to just give up and stop trying. The trick is to have the right level and degree of difficulty to engage the students and not frustrate them. The coach really helped us here. Learning how to help the girls feel comfortable to keep trying and not give up; that was the most useful to me."

Intern \#3: "I found the instructional coach to be the most useful aspect of the camp experience. She was very helpful and gave us such good ideas and pointers. The opportunity to plan with her made the lessons run so much more smoothly. I 
really had no idea how to plan for what we were trying to do... without the coach the lessons would not have been on target. I had never taught real kids, I didn't know where to start."

Intern \# 5: "Maybe I had worked with some small groups of students in tutoring sessions, but nothing like the Eureka! STEM Camp. This was hands on teaching with real kids. All different, very diverse groups of girls. The issue for me was how to relate? How do I get to know the girls? What do I talk about? The instructional coach was great. She helped us with all kinds of teaching strategies and ice breaker activities to get a feel for the students."

Intern \# 7: "For me it was all about the coaching in the process of teaching math or any other subject. The sessions we helped with were assigned. The coach attended the sessions and observed us working with the girls. After the sessions, she would debrief with us about how the sessions had gone. We had time to ask questions and discuss anything we wanted to talk about."

\section{Assertion Four}

The need for experience in teaching and the support to try new strategies was very useful to the interns. It was emphasized by the interns that having help with the selection of the teaching strategies and the implementation was critical to developing efficacy about teaching mathematics.

Intern \#10: "The lack of experience teaching real kids math or anything else for that matter...really made it hard at first to pick or plan good lessons. The coaching was very important to me. It made it much easier to see myself being successful."

Intern \#1: "I needed help selecting the lessons and working with curriculum materials. How do you find activities to teach the math concepts in a way that is both engaging and allows the girls opportunity to problem solve? This was for me the big challenge."

Intern \#2: "Most of us came into the (Camp name) experience with limited exposure to teaching. We all felt overwhelmed at first. The girls we were working with were not like what I had experience with in my own school back home. Even with all the stress, I would do it again. The learning curve was steep, but the rewards outweighed the stress." 


\section{Discussion}

Implications

There is limited research about the mathematics teaching self-efficacy of preservice secondary teachers, especially compared with the literature about preservice elementary teachers. This study illustrates the need for more. It is relevant to teacher training programs, particularly those at metropolitan universities, but also for any program where students are interested in teaching at high-needs schools.

The authors found that preservice secondary teachers, even though they have high mathematics skills, still feel anxious and unprepared to actually teach mathematics to real students. This is especially true when those students come from underserved populations and different cultural backgrounds from the preservice teachers.

Two elements of the study offer contributions to the understanding of teaching self-efficacy in preservice teachers. One was exploring issues with secondary mathematics teachers previously explored with elementary science teachers (Franks, McGlamery, \& Van Wyngaarden, 2016; McGlamery, Franks, \& Shillingstad, 2016). As with those studies, it was found that the summer camp experience resulted in significant improvements in teaching self-efficacy. Another contribution was utilizing qualitative methods to discover more about what specific experiences meant the most to preservice teachers, and had the most effect on their self-efficacy. Among those experiences, the supervision and support of an instructional coach ranked highly, as did the opportunity to work with ethnically and culturally diverse students.

\section{Limitations and Future Studies}

One obvious limitation of this study is the small sample size. Another is the fact that all the interns were scholarship recipients and, therefore, high achieving students in mathematics. Future studies should explore the self-efficacy of a broader range of preservice secondary mathematics teachers. This would have to be done during a regular school semester, however, since the summer camp could not be staffed by many more people.

In both the summer camp and in a classroom-based field experience, the authors found positive effects on science teaching self-efficacy, as measured by the Science Teaching Efficacy Beliefs Instrument, or STEBI (Enochs \& Riggs, 1990), in preservice elementary science teachers (Franks, McGlamery, \& Van Wyngaarden, 2016; McGlamery, Franks, \& Shillingstad, 2016; McGlamery \& Franks, 2019). The next step is to assess teaching self-efficacy with preservice secondary teachers in both mathematics and science during a regular school semester. This study

(C) The Author 2021. Published by the Coalition of Urban and Metropolitan Universities. www.cumuonline.org 
provided a deeper exploration by using qualitative methods; those, too, should be utilized with classroom-based field experiences.

The Importance of Community Partnerships in Teacher Education Programs

Our metropolitan university has a long history of service learning and community partnerships (Schumaker \& Woods, 2001; Woods, Reed, \& Smith-Howell, 2016), particularly with regard to STEM education (Grandgennett et al., 2015). This study illustrates that such partnerships can enhance teacher training when field placements include community-based organizations other than schools. As McDonald et al. (2011) observed, such placements "afforded preservice teachers new ways of seeing and understanding children beyond school and across difference." They build connections between prospective teachers and community organizations, helping them to develop a holistic and assets-based view of children and youth.

The interns in this study experienced the connections made in a community partnership between a service/mentoring organization for girls and their own metropolitan university. A significant benefit of the partnership in this case was the opportunity for informal interactions between middle-class education students and the underserved students they will be teaching in the future. Spending full days with their students in a summer camp setting, including field trips and social activities, allowed the interns to stretch their interpersonal skills, and raised their awareness of the need for developmentally appropriate lessons. It allowed them to teach students from three very distinct cultural groups (Latinx, Somali, and African American) in the city. Because most of them came from White, middle-class families, but wished to teach in the city's ethnically diverse public school district, this early experience with students from different cultures was invaluable.

Education students ultimately have many opportunities to go out into their communities because they have field experiences in different schools throughout their training. In the case of the summer camp, an important community connection was bringing the girls to the campus. For some, it was their first time being on a college campus, so preservice teachers were able not only to teach them, but also to serve as role models, inviting the girls to see themselves in the role of college student in the future.

\section{Conclusion}

This study describes a unique program that addresses the opportunity gaps experienced by highneeds students by providing both pre-college experiences and community partnerships (Reding et al., 2017. Such programs benefit both student participants and preservice teachers because of the demand for STEM teachers in high-needs educational environments. If teacher education programs are to be successful in training teachers who can be effective mathematics educators in high-needs schools, those preservice teachers need support, and that support should begin early

(C) The Author 2021. Published by the Coalition of Urban and Metropolitan Universities. www.cumuonline.org Metropolitan Universities | DOI 10.18060/25396 | August 16, 2021 
in their teacher preparation. Even though the Eureka! STEM Camp lasted for only four weeks, it gave these preservice teachers both a real-life experience with a culturally diverse group of students, and the support to improve their self-efficacy for teaching the students who will need them most. 


\section{References}

Bandura, A. (1986). Social Foundations of Thought and Action: A Social Cognitive Theory. Prentice Hall. https://doi.org/10.1017/s0813483900008238

Bates, A. B., Latham, N., \& Kim, J. (2011). Linking preservice teachers' mathematics selfefficacy and mathematics teaching efficacy to their mathematical performance. School Science and Mathematics, 111(7), 325-333. https://doi.org/10.1111/j.1949$\underline{8594.2011 .00095 . x}$

Bogdan, R. \& Biklen, K. (2007). Qualitative Research for Education: An Introduction to Theory and Methods. Pearson. https://www.pearson.com/us/higher-education/program/BogdanQualitative-Research-for-Education-An-Introduction-to-Theories-and-Methods-5thEdition/PGM125872.html?tab=order

Bol, L., \& Berry, R. Q. (2005). Secondary school teachers' perceptions of the achievement gap. The High School Journal, 88(4), 32-45. https://doi.org/10.1353/hsj.2005.0007

Briley, J. S. (2012). The relationships among mathematics teaching efficacy, mathematics selfefficacy, and mathematical beliefs for elementary pre-service teachers. Issues in the Undergraduate Mathematics Preparation of School Teachers: the Journal, 5, 1-13. https://www.depts.ttu.edu/math/

Buss, R. R. (2010). Efficacy for teaching elementary science and mathematics compared to other content. School Science and Mathematics, 110(6), 290-297. https://doi.org/10.1111/j.1949-8594.2010.00037.x

Creswell, J. W., \& Guetterman, T. C. (2019). Educational Research: Planning, Conducting, and Evaluating Quantitative and Qualitative Research. Pearson. https://www.pearson.com/store/p/educational-research-planning-conducting-andevaluating-quantitative-and-qualitativeresearch/P100001431982/9780136874416? creative $=490049774056 \&$ keyword $=$ \&matchty pe $=$ \&network $=$ g\&device $=$ c\&gclid $=$ EAIaIQobChMI86CbyaLX8AIV2vjBx1VkQjzEAQYASABEgLiR_D_BwE

Cohen, J. (1988). Statistical power analysis for the behavioral sciences. Erlbaum. https://doi.org/10.4324/9780203771587 
Enochs, L. G., \& Riggs, I. M. (1990). Further development of an elementary science teaching efficacy belief instrument: A preservice elementary scale. School Science and Mathematics, 90(8), 694-706. https://doi.org/10.1002/sce.3730740605

Enochs, L. G., Smith, P. L., \& Huinker, D. (2000). Establishing factorial validity of the Mathematics Teaching Efficacy Beliefs Instrument. School Science and Mathematics, 100(4), 194-202. https://doi.org/10.1111/j.1949-8594.2000.tb17256.x

Evans, B. R. (2011a). Content knowledge, attitudes, and self-efficacy in the mathematics New York City Teaching Fellows (NYCTF) program. School Science and Mathematics, 111(5), 225-235. https://doi.org/10.1111/j.1949-8594.2011.00081.x

Evans, B. R. (2011b). Secondary mathematics teacher differences: Teacher quality and preparation in a New York City alternative certification program. The Mathematics Educator, 20(2), 24-32. https://openjournals.libs.uga.edu/tme

Flores, A. (2007). Examining disparities in mathematics education: Achievement gap or opportunity gap? The High School Journal, 91(1), 29-42. https://doi.org/10.1353/hsj.2007.0022

Franks, B., McGlamery, S., \& VanWyngaarden, K. (2016). Effects of teaching in a science summer camp on the science self-efficacy of preservice teachers. Delta Kappa Gamma Bulletin, 82(3), 63-73. https://www-proquestcom.leo.lib.unomaha.edu/docview/1770514320/7AC88C2C536742C2PQ/12?accountid= $\underline{14692}$

Grandgennett, N., Edick, N., Boocker, D., Ali, H., Hodge, A., Dorn, B., \& Cutucache, C.(2015). Community chairs as a catalyst for campus collaborations in STEM. Metropolitan Universities, 26(1), 71-96. https://journals.iupui.edu/index.php/muj/article/view/20989

Hackett, G., \& Betz, N. E. (1989). An exploration of the mathematics self-efficacy/mathematics performance correspondence. Journal for Research in Mathematics Education, 20, 261273. https://doi.org/10.2307/749515

Haynes, J. C., \& Stripling, C. T. (2014). Mathematics efficacy and professional development needs of Wyoming agricultural education teachers. Journal of Agricultural Education, 55(5), 48-64. https://doi.org/10.5032/jae.2014.05048

Karp, K. S. (1991). Elementary school teachers' attitudes towards mathematics: The impact on students' autonomous learning skills. School Science and Mathematics, 91, 265-270. https://doi.org/10.1111/j.1949-8594.1991.tb12095.x 
Kotok, S. (2017). Unfulfilled potential: High-Achieving minority students and the high school achievement gap in math. The High School Journal, 100(3), 183-202. https://doi.org/10.1353/hsj.2017.0007

Locke, L. A., Tabron, L. A., \& Venzant Chambers, T. T. (2017). "If you show who you are, then they are going to try to fix you": The capitals and costs of schooling for high-achieving Latina students. Educational Studies, 53(1), 13-36. https://doi.org/10.1080/00131946.2016.1261027

McDonald, M. A., Tyson, K., Brayko, K., Bowman, M., Delport, J., \& Shimomura, F. (2011). Innovation and impact in teacher education: Community-Based organizations as field placements for preservice teachers. Teachers College Record, 113(8), 1668-1700. https://www.tcrecord.org ID Number: 16162

McGlamery, S., \& Franks, B. A. (2019). Comparing practicum experiences in science methods courses: Effects of field on science teaching efficacy. Paper presented at the National Association for Research in Science Teaching Conference International, April 2019.

McGlamery, S., Franks, B. A., \& Shillingstad, S. L. (2016). Teacher training in urban settings: Inquiry, efficacy, and culturally diverse field placements. Metropolitan Universities, 27(1), 44-55. https://journals.iupui.edu/index.php/muj/article/view/21116/20521

National Center for Educational Statistics, May 2020 https://nces.ed.gov/programs/coe/indicator_clr.asp

National Council of Teachers of Mathematics, (2012). https://www.nctm.org/Standards-andPositions/Position-Statements/Closing-the-Opportunity-Gap-in-Mathematics-Education/

Nebraska Department of Education https://www.education.ne.gov/assessment/

Newton, K. J., Leonard, J., Evans, B. R., \& Eastburn, J. A. (2012). Preservice elementary teachers' mathematics content knowledge and teacher efficacy. School Science and Mathematics, 112(5), 289-299. https://doi.org/10.1111/j.1949-8594.2012.00145.x

Omaha Public Schools https://district.ops.org/DEPARTMENTS/General-Finance-andAdministrative-Services/Research/Statistical-Reports

Reding, T. E., Squires, A., Grandgennett, N., Keller, S., Grandgennett, H., Hodge, A., Argo, C., \& Jacobberger, K. (2017). Determining quantity and strength of relationships between 
STEM camp participants and the math student camp leaders. International Journal of Research in Education and Science, 3(1), 171-179).

https://www.ijres.net/index.php/ijres/article/view/144

Schumaker, A., \& Woods, S. (2001). The role of a college in a university-wide approach to community partnerships: The University of Nebraska at Omaha Experience. Metropolitan Universities, 12(4), 66-79 https://journals.iupui.edu/index.php/muj/article/vie917

Smith, P. S., Trygstad, P. J., \& Banilower, E. R. (2016). Widening the gap: Unequal distribution of resources for K-12 science instruction. Education Policy Analysis Archives, 24(8). http://dx.doi.org/10.14507/epaa.v24.2207

Swars, S. L., Daane, C. J., \& Giesen (2006). Mathematics anxiety and mathematics teacher efficacy: What is the relationship in elementary preservice teachers? School Science and Mathematics, 106(7), 306-315. https://doi.org/10.1111/j.1949-8594.2012.00145.x

Swars, S. L., Hart, L. C., Smith, S. Z., Smith, M. E., \& Tolar, T. (2007). A longitudinal study of elementary pre-service teachers' mathematical beliefs and content knowledge. School Science and Mathematics, 107(8), 325-335. https://doi.org/10.1111/j.1949$\underline{\text { 8594.2007.tb17797.x }}$

Tabron, L. A., \& Venzant Chambers, T. T. (2019). What is being black and high achieving going to cost me in your school? Students speak out about their educational experiences through a racial opportunity cost lens. High School Journal, 102(2). https://doi.org/10.1353/hsj.2019.0002

Utley, J., Mosely, C., \& Bryant, R. (2005). Relationship between science and mathematics teaching efficacy of preservice elementary teachers. School Science and Mathematics, 105, 82-87. https://doi.org/10.1111/j.1949-8594.2005.tb18040.x

Woods, S., Reed, B. J., \& Smith-Howell, D. (2016). Building an engagement center through love of place: the story of the Barbara Weitz Community Engagement Center. Metropolitan Universities, 27(3), 85-105. DOI10.18060/21388 https://journals.iupui.edu/index.php/muj/article/view/21379 